\title{
Análise do Comportamento e Sociedade: Implicações para uma Ciência dos Valores
}

Behavior Analysis And Society: Implications For A Science Of Values

Análisis Del Comportamiento Y Sociedad: Implicaciones Para Una Ciencia De Los Valores

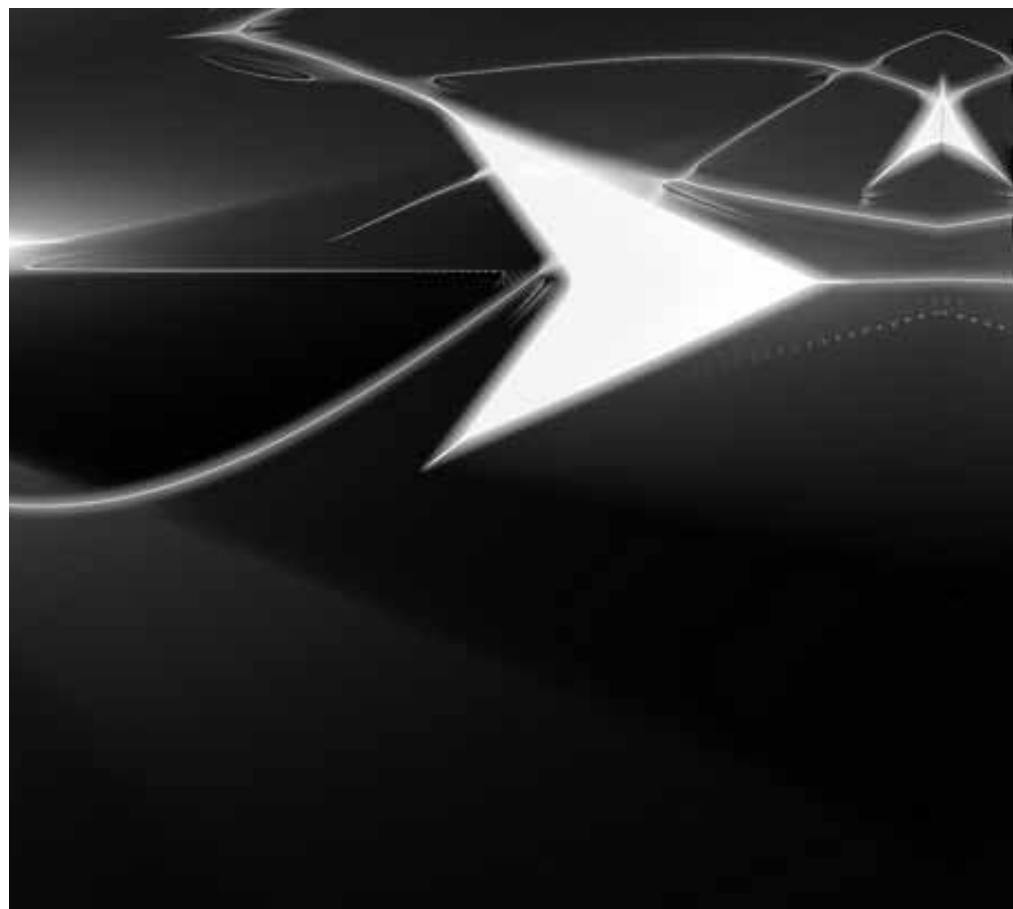


Resumo: O behaviorismo radical tem sido alvo de muitas críticas, principalmente no que se refere às questões éticas. A despeito dessas críticas, Skinner considera a análise do comportamento uma ciência dos valores, discutindo a moralidade em termos de comportamento moral. Entretanto, a afirmação de que a análise do comportamento é uma ciência dos valores pode ter consequências sociais distintas a depender do modelo de ciência adotado como pressuposto. O debate científico contemporâneo trata da crise do modelo moderno de ciência e do surgimento de outro: o modelo pós-moderno. Uma das diferenças entre essas duas propostas científicas refere-se à relação entre ciência e sociedade. Considerando esses aspectos, o objetivo deste trabalho é discutir qual modelo de ciência, moderno ou pós-moderno, norteia a assertiva skinneriana que declara a análise do comportamento uma ciência dos valores. Para tanto, serão apresentadas, inicialmente, algumas concepções tradicionais de explicação do comportamento moral e as principais críticas que Skinner dirige a elas. Em seguida, o sistema ético skinneriano será analisado, juntamente às questões sociais envolvidas na prática do analista do comportamento. E, por fim, discutir-se-á como cada modelo de ciência pode subsidiar práticas de intervenção diferentes, com consequências sociais igualmente distintas. Palavras-chave: Ciência. Sociedades. Comportamento social. Análise do comportamento. Valores sociais.

\begin{abstract}
Radical behaviorism has attracted a lot of criticism, mainly when it comes to ethical issues. Despite the criticism, Skinner considers the behavior analysis a science of values, discussing morality in terms of moral behavior. However, the claim that the behavior analysis is a science of values may have distinctive social consequences depending on the model of science to be assumed. The contemporary scientific debate is about the crisis of the modern model of science and the emergence of another: the postmodern model. One of the differences between these two scientific proposals refers to the relation between science and society. Considering these aspects, the objective of this paper is to discuss which model of science, modern or postmodern, based on the skinnerian statement which declares the behavior analysis a science of values. To do so, initially, some traditional conceptions explaining moral behavior, and the main criticism that Skinner directs to them will be presented. Then, Skinner's ethical system will be analyzed, along with the social issues involved in the behavior analyst's practice, and, finally, the paper will discuss how each model of science can support different intervention practices, with equally distinct social consequences.
\end{abstract}

Keywords: Science. Societies. Social behavior. Behavior analysis. Social values.

Resumen: El behaviorismo radical ha sido objetivo de muchas críticas, principalmente en lo que se refiere a las cuestiones éticas. Al respeto de esas críticas, Skinner considera el análisis del comportamiento una ciencia de los valores, discutiendo la moralidad en términos de comportamiento moral. No obstante, la afirmación de que el análisis del comportamiento es una ciencia de los valores puede tener consecuencias sociales distintas dependiendo del modelo de ciencia adoptado como supuesto. El debate científico contemporáneo trata la crisis del modelo moderno de ciencia y del surgimiento de otro: el modelo postmoderno. Una de las diferencias entre estas dos propuestas científicas se refiere a la relación entre ciencia y sociedad. Considerando esos aspectos, el objetivo de este trabajo es discutir qué modelo de ciencia, moderno o postmoderno, nortea la asertiva skinneriana que declara el análisis del comportamiento una ciencia de los valores. Para eso, serán presentadas, inicialmente, algunas concepciones tradicionales de explicación del comportamiento moral y las principales críticas que Skinner dirige a ellas. Enseguida, el sistema ético skinneriano será analizado, juntamente a las cuestiones sociales involucradas en la práctica del analista del comportamiento. Y, por fin, se discutirá como cada modelo de ciencia puede subvencionar prácticas de intervención diferentes, con consecuencias sociales igualmente distintas.

Palabras clave: Ciencia. Sociedades. Conducta social. Análisis del comportamiento. Valores sociales.

O behaviorismo radical foi e continua sendo alvo de inúmeras críticas (Carrara, 2005). Uma delas esbarra em questões éticas, como se vê em declarações que acusam o behaviorismo skinneriano de reacionário, antidemocrático e incapaz de lidar com valores (Carrara, 2005, pp. 280-329). Skinner (1971/1972) impugna essas críticas e, ao fazer isso, demarca seu posicionamento ético. Para entender esse posicionamento, é preciso, antes de tudo, examinar algumas concepções de ética criticadas por ele, notadamente aquelas que recorrem a causas internas para explicar o comportamento moral. Essa concepção tradicional de ética, argumenta Skinner, tem consequências sociais funestas, e é responsável pela manutenção da desigualdade social (Holland, 1978).

Na contramão de seus detratores, o behaviorismo radical defende a ideia de que a ciência do comportamento não deve 
se apartar da discussão ética. Isso fica claro quando o próprio Skinner afirma que a análise do comportamento é uma "ciência dos valores" (1971/1972, p. 85). Sob essa ótica, a moralidade é tratada em termos de comportamento moral, e os valores como consequências de ações morais. Com efeito, o behaviorismo radical aproxima ciência de valores e, por conseguinte, ciência de sociedade: a relação entre a análise do comportamento e a sociedade é inerente "aos próprios propósitos de uma ciência do comportamento aplicada ao homem" (Holpert, 2004, p. 11). Tratar a moralidade do ponto de vista comportamentalista tem sérias implicações, pois encoraja a abordar os problemas sociais recorrendo às relações do homem com o mundo, e não mais às causas internas, usualmente empregadas para converter questões de natureza social em problemas individuais. Skinner exemplifica:

O apelo a estados e processos cognitivos é um desvio que pode muito bem ser o responsável por muitas de nossas falhas em resolver nossos problemas. Precisamos mudar nosso comportamento e podemos fazê-lo somente mudando nossos ambientes físico e social. Escolhemos o caminho errado, logo de início, quando supomos que nosso objetivo é mudar as 'mentes e corações dos homens e mulheres' ao invés do mundo no qual eles vivem. (1978, p. 112)

Desse modo, a declaração skinneriana de que a análise do comportamento é uma ciência dos valores sugere, no limite, que a ciência não pode se eximir do debate ético e social. Não obstante, essa afirmação de Skinner (1971/1972) pode ter consequências distintas para a relação entre ciência e sociedade a depender do modelo de ciência adotado. O debate científico contemporâneo trata da crise do modelo científico moderno e do surgimento de um modo diferente de fazer ciência, denominado por alguns de ciência pós-moderna (Santos, 2002). Uma das diferenças entre essas duas propostas científicas esbarra justamente na relação entre ciência e sociedade. Tendo em vista a discussão dos diferentes modelos de ciência, o objetivo deste artigo é examinar possíveis encaminhamentos para a assertiva skinneriana de que a análise do comportamento é uma ciência dos valores. Em suma, a pergunta que está no horizonte desse debate é esta: se a análise do comportamento é uma ciência dos valores, qual modelo de ciência orienta essa afirmação? Moderno ou pós-moderno? A resposta a essa questão interessa à análise do comportamento, pois suscita uma reflexão acerca do tipo de relação que o analista do comportamento pode estabelecer com a sociedade.

\section{A teoria do homem autônomo e o mito das causas internas}

Comumente, o comportamento humano é explicado recorrendo-se a sentimentos ou a estados de espírito (Oliveira, 2001; Skinner, 1971/1972). A teoria do homem autônomo considera que o comportamento do indivíduo seja uma realização pessoal. A pessoa é livre para deliberar, decidir, agir. De acordo com essa concepção, os sentimentos são parte constituinte do homem autônomo, e explicam o seu comportamento. Essa tese tem expressões no contexto da moralidade. No que se refere ao comportamento moral, a teoria do homem autônomo fundamenta explicações que recorrem a alguma virtude interior para justificar por que alguém procede bem em relação aos outros; alguma noção de responsabilidade, obrigação, lealdade ou respeito para com os demais. Do mesmo modo, quando alguém deixa de agir pelo bem de seus companheiros, diz-se que sofre de falta de valores, que é tradicionalmente descrita "como anomia, amoralidade, anedonia, desarraigamento, vazio, desesperança, ou falta de algo em que crer ou a que se devotar" (Skinner, 1971/1972, p. 96).

Essa explicação tradicional da moralidade fica evidente em diferentes situações. 
Se os estudantes não respondem mais satisfatoriamente aos ambientes educacionais, por exemplo, diz-se que é necessário cultivar um respeito pelo conhecimento e pelo educador. Se os jovens se recusam a servir às forças armadas, diz-se que é necessário inspirar lealdade e patriotismo; se as nações estão em guerra, diz-se que devemos atacar "as tensões que levam à guerra" ou transformar o modo de pensar dos homens que está propenso à guerra; se os jovens trabalham pouco, os trabalhadores não são produtivos; se os produtos são comumente de má qualidade, diz-se que é necessário inspirar "um senso de arte profissional ou orgulho pelo trabalho de alguém" ou um "senso de dignidade do trabalho" (Skinner, 1971/1972, p. 126).

Outro exemplo da explicação do comportamento em termos do homem autônomo encontra-se em análises sobre a violência. Sobre esse ponto, Carvalho Neto, Alves e Baptista (2007) apresentaram uma declaração de José Gregori, no ano 2000. Nessa ocasião, Gregori era Ministro da Justiça do Governo Fernando Henrique Cardoso, e atribuiu parte da responsabilidade pelo aumento da violência à "falta de 'consciência' dos cidadãos comuns" (p. 28). Nessa perspectiva, a solução apresentada para o problema seria, então, a "conscientização de todos" (p. 29) acerca de seu papel na sociedade e da responsabilidade de respeitar as leis. A violência é explicada, aqui, pela ausência da consciência: uma força interna que regula as ações humanas e que direciona o comportamento para o bem comum. Sem a consciência, restaria o padrão egoísta que levaria aos crimes.

A noção de homem autônomo subjaz ao mito das causas internas, um modo de explicação que converte problemas de natureza social em questões puramente individuais. Holland (1978) ressalta que o mito das causas internas é promovido pelo reforço fornecido à elite e pela manutenção do sistema atual, ou seja, está atrelado a uma questão ideológica (Szasz, 1970/1980). Diz-se, por exemplo, que aqueles que estão no alto da hierarquia do poder chegaram lá por mérito pessoal, pois o rico é livre para usar seus recursos internos, seu desejo, determinação, motivação e inteligência. Por outro lado, um conjunto especial de causas internas foi reservado aos pobres: são preguiçosos, não têm ambição, não são talentosos.

Diante disso, vale ressaltar que o behaviorismo radical rejeita "definitivamente a figura do homem interior [itálicos do autor] como protótipo das explicações causais envolvendo sentimentos, estados da mente e processos ou estruturas mentais" (Carrara, 2005, p. 307). Para Skinner, explicações como as citadas acima, que aludem a causas internas, apresentam dois defeitos característicos que levam ao fracasso em lidar adequadamente com problemas culturais: o comportamento perturbado não é, de fato, descrito, e não se menciona o que pode ser feito para mudar. O que está errado é o ambiente educacional, as contingências que induzem os jovens a proceder de determinada maneira para com seu governo, as circunstâncias nas quais os homens e as nações fazem a guerra, as contingências que incitam o homem a trabalhar com aplicação e cuidado (Skinner, 1971/1972). Desse modo, as causas ou as explicações do comportamento não podem ser encontradas no interior do indivíduo. Contudo, declarar isso não implica sustentar que a explicação do comportamento resida exclusivamente na alusão ao ambiente externo. Ao contrário, o behaviorismo skinneriano advoga um modo de explicação relacional. Em outras palavras, a explicação do comportamento não está calcada no ambiente interno e tampouco no externo, mas sim, na relação homem-mundo (Oliveira, 2001; Tourinho, 2006). Tourinho explicita esse aspecto ao dizer que: 
frente às dicotomias psicológicas clássicas, o público versus o privado, o interno versus o externo, o físico versus o mental, e o objetivo versus o subjetivo, dependentes antes de tudo de uma noção mais básica de afastamento entre indivíduo e sociedade, um analista do comportamento não tomará partido por nenhuma das referências. No lugar disso, lembrará que essas categorizações não se aplicam ao seu objeto: as relações organismo-ambiente, ou mais especificamente, as relações homemambiente. (Tourinho, 2006, p. 2)

Com efeito, as questões éticas e sociais devem ser avaliadas à luz dessa perspectiva relacional. Problemas sociais são problemas da relação do homem com o mundo, e não problemas do ou no indivíduo, ou problemas do ou no ambiente.

\section{A proposta ética skinneriana e seus desdobramentos sociais}

Skinner (1971/1972) propõe uma ética orientada pelos conceitos da ciência do comportamento, considerando-a uma ciência dos valores. Como foi mencionado alhures, os valores são definidos em termos das consequências produzidas pelo comportamento. Para entender essa tese, é preciso antes subsumi-la, ainda que brevemente, a outra discussão, que trata do modelo por meio do qual Skinner (1981) explica o comportamento, denominado seleção pelas consequências. Analogamente à teoria darwiniana da evolução pela seleção natural, o modelo de seleção pelas consequências explica a origem e a evolução de diferentes "espécies de comportamentos" (Abib, 2008, p. 3): os comportamentos da espécie que surgem na filogênese, como os reflexos incondicionados e os instintos, os comportamentos que se originam na história de vida do indivíduo, a exemplo do operante, e os comportamentos que se constituem na temporalidade da evolução de ambientes sociais especiais chamados culturas, como as práticas culturais. Essas diferentes espécies de comportamento originam-se e evoluem por meio dos processos de variação e de seleção. Basicamente, o processo global parece ser o seguinte: variações que acontecem nas relações da espécie, do indivíduo e da cultura com seus respectivos contextos são selecionadas por consequências que tornem essa inter-relação mais eficaz.

No âmbito do debate ético e moral, essa interrelação é chamada de boa ou valorosa. Em outras palavras, a problemática dos bens e dos valores também é discutida por Skinner à luz do modelo de seleção pelas consequências. Do ponto de vista filogenético, o que é bom para a espécie é tudo aquilo que promove a sobrevivência de seus membros "até que sua prole tenha nascido e, possivelmente, sido criada" (Skinner, 1981, p. 503). Nessa ótica, foi bom para a sobrevivência da espécie o desenvolvimento de uma susceptibilidade ao reforçamento por coisas que tivessem um bom sabor ou que gerassem sensações agradáveis. No contexto de sua história de vida, o que é bom para o indivíduo são comportamentos que produzam consequências reforçadoras positivas sob as contingências em vigor. Já "o que é bom para uma cultura é qualquer coisa que promova sua sobrevivência última, como manter um grupo coeso ou transmitir suas práticas" (Skinner, 1981, p. 503). Desse modo, o bem de uma espécie e de uma cultura são consequências que promovam a sua sobrevivência, ao passo que o bem do indivíduo são as consequências reforçadoras que mantenham operantes que permitam ao homem lidar efetivamente com as contingências de sua vida.

O modelo de seleção pelas consequências, ao descrever os valores em termos de consequências filogenéticas, ontogenéticas e culturais, traz nova luz para a compreensão dos conflitos éticos enfrentados atualmente pelo homem (Holpert, 2004; Skinner, 1981). Mais especificamente, os problemas 
éticos podem ser esclarecidos por meio da descrição das contradições entre os três níveis seletivos (Holpert, 2004). Uma forte suscetibilidade a ser reforçado por açúcar, por exemplo, já foi importante para a sobrevivência da espécie. Entretanto, hoje a capacidade de ser reforçado por doces pode levar o indivíduo a comer demais, gerando mal-estar, e, mais tardiamente, obesidade e outras doenças. Em outras palavras, o que foi bom para a espécie pode gerar consequências aversivas para comportamentos do indivíduo relacionados à ingestão de doces. Outra situação: o que é bom para o indivíduo, como o reforçamento por contato sexual, pode produzir consequências que são danosas para a cultura e, em última instância, para a própria sobrevivência da espécie, a exemplo da superpopulação.

Considerando a possibilidade de conflito entre bem da espécie, bem do indivíduo e bem da cultura, o que é ser ético para Skinner? É produzir consequências consistentes com a sobrevivência da espécie? É produzir consequências reforçadoras que mantenham comportamento operante efetivo em contingências prevalecentes? É promover consequências que garantam o bem da cultura? Nesse ponto, Skinner (1971/1972) é prescritivo: o bem mais fundamental de sua teoria ética é o bem da cultura. Agir pelo bem da cultura é agir pela sua sobrevivência. Afastando possíveis filiações dessa tese ao darwinismo social, Abib, apoiando-se em Skinner, esclarece que agir para o bem da cultura: “. . . é agir para a sobrevivência das culturas, e isso significa, no mínimo, proteger a cultura de práticas para ela letais, como superpopulação, devastação do meio ambiente, poluição e a possibilidade de holocausto nuclear" (2001, p. 108). O termo sobrevivência usualmente remete à competição, como quando se afirma que a luta pela sobrevivência da espécie envolve a competição com outras espécies por um lugar ao sol. Vale ressaltar que a noção de sobrevivência adquire uma conotação bem específica na teoria moral skinneriana: a sobrevivência das culturas alude à competição entre práticas, e não entre membros e entre culturas. Por exemplo, a competição se dá entre práticas culturais que incitam a violência, letal aos indivíduos e às culturas, e práticas que fomentem o pacifismo, condizentes com a sobrevivência dos indivíduos e das culturas (Abib, 2001).

A despeito de sua importância, a prescrição skinneriana com respeito à sobrevivência das culturas traz problemas suplementares. Como agir pelo bem da cultura se a sua sobrevivência é uma consequência postergada a ponto de poder ultrapassar o tempo de vida do indivíduo? Essa questão é embaraçosa, pois a análise do comportamento ampara-se em uma discussão biológica e comportamental para mostrar a eficiência das consequências imediatas na instalação e na modificação do comportamento (Skinner, 1981). De uma perspectiva biológica evolucionária, a susceptibilidade do indivíduo às consequências imediatas é uma herança filogenética: na história da espécie, as consequências imediatas tiveram maior valor de sobrevivência quando comparadas às postergadas (Abib, 2001). Essa capacidade de o organismo ser afetado predominantemente por consequências imediatas manifestase na história individual. Um exemplo do cotidiano pode ilustrar esse ponto. $\mathrm{O}$ comportamento de uma pessoa de fumar cigarros presumivelmente é mais afetado por consequências contemporâneas, como a eliminação de sua ansiedade (reforçador negativo) ou prestígio social (reforçador positivo) do que por consequências em longo prazo, como doenças respiratórias decorrentes da prática de fumar. Essa sensibilidade herdada às consequências imediatas também está na base de algumas práticas culturais que acabam acentuando esse imediatismo - como é o caso do consumo 
desenfreado, característico da sociedade ocidental capitalista. Não obstante, parece que o imediatismo promovido pela cultura realça práticas calcadas em comportamentos que colocam em risco a própria natureza ou a sobrevivência da espécie. Em outras palavras, tem-se, de um lado, um prolongamento do imediatismo da natureza na cultura, e, por outro, algumas práticas culturais que exacerbam esse imediatismo fortalecendo comportamentos individuais que ameaçam a sobrevivência da espécie e da própria cultura (Abib, 2001).

Diante disso, como superar a barreira da temporalidade de consequências atrasadas como a sobrevivência das culturas? A tarefa que se apresenta para os analistas do comportamento é a de lidar com a relação desigual entre sensibilidade às consequências imediatas, que ameaçam a sobrevivência das culturas, e certa indiferença às consequências postergadas, que promovam essa sobrevivência. Uma das maneiras de enfrentar esse desafio é organizar práticas culturais que tragam o futuro para o presente, ou, em termos skinnerianos, encontrar "substitutos atuais das consequências mais remotas de nosso comportamento" (Skinner, 1989 , p. 120). Recuperando o exemplo do hábito de fumar, trata-se de trazer as consequências aversivas do fumar para a situação contemporânea (Abib, 2001), de modo que elas ajam como se o futuro agisse e estivesse aqui agora (Skinner, 1990b): aumenta-se o preço de cigarros, restringemse os locais permissivos ao fumo e fomentamse comentários que retiram o glamour e a sofisticação que outrora envolviam o ato de fumar. Por outro lado, trata-se também de fortalecer comportamentos inconsistentes com o fumar: elogia-se a diminuição do ato de fumar, acentuam-se os efeitos benéficos da interrupção do fumo, como a melhoria no paladar, no olfato, e assim por diante.
Skinner (1990b) declara queé responsabilidade de instituições como governo, indústria, e religião engajar-se nessas práticas. Além delas, Skinner (1989, p. 120) chama a atenção para o importante papel desempenhado por um "quarto estado" composto pela mídia, professores, acadêmicos e cientistas nessa empreitada. Abib destaca que esse quarto estado, notadamente os cientistas, dispõe de formas menos institucionalizadas de controle, "como as relações de 'controle pessoal face a face'" (2001, p. 107) para promover práticas culturais que sejam consistentes com o valor de sobrevivência das culturas. Nesse contexto, o psicólogo, como um cientista, ao apresentar "domínio da ciência e tecnologia do comportamento", tem "condições, portanto, de defender o bem da cultura" (Abib, 2001, p. 107).

Para atuar de maneira consistente com o bem da cultura, é preciso que o analista do comportamento faça um exame crítico das contingências sociais envolvidas na aquisição e na manutenção do comportamento geralmente tido como perturbado. Sobre esse ponto, alguns autores, como, Gongora (2003), Holland (1978), Szasz (1970/1980) e Ullman e Krasner (1975), por exemplo, apontam a necessidade de explicar o comportamento normal ou anormal recorrendo a contingências sociais, e não a causas internas, considerando que são comportamentos aprendidos, e que são classificados de acordo com o momento social e ideológico. Holland exemplifica essa questão citando comportamentos como os de beber e de praticar crimes. Não obstante, alerta que o próprio analista do comportamento deve considerar que seu comportamento de tentar lidar com esses problemas está também submetido a tal controle. Desconsiderar isso pode fazer com que o analista do comportamento seja não a solução, mas a parte constituinte dos problemas sociais que deseja, a princípio, superar. 
Comumente, diz Holland (1978), o problema do alcoolista é descrito como beber, e supõese que submetê-lo ao condicionamento aversivo poderia curar esse hábito. No entanto, um estudo descrito pelo autor com pacientes alcoolistas sugere outra definição do problema. De 210 pacientes, apenas 31 viviam com alguma companhia (esposa, parentes, ou amigos), e a maioria não tinha residência fixa. Eles eram pobres, não tinham emprego, e estavam com problemas físicos graves. Em geral, os pacientes pareciam ser infelizes e solitários. Mas o profissional, ao considerar que o álcool seja o problema, trata direta e apenas dele, esquecendo-se de que, se algo precisa ser mudado para solucionar o problema, são as contingências sociais. E, nessas condições, o alcoolismo pode ser considerado um comportamento adaptativo. Em nossa cultura, beber produz consequências reforçadoras. Em festas e ambientes amigáveis, as pessoas seguram coquetéis; quando algo precisa ser resolvido, sentam para tomar cerveja; quando um garoto se aproxima de uma garota, frequentemente oferece uma bebida. Nessas circunstâncias, o álcool serve como estímulo discriminativo de reforço. A resolução desse problema requer, então, uma mudança nas contingências ambientais que envolvam atividades diárias e práticas culturais (Holland, 1978; Skinner, 1971/1972; Szasz, 1970/1980; Ullman \& Krasner, 1975).

Com respeito ao fato de cometer crimes, Holland destaca que o sistema prisional tem como objetivo a correção de falhas de personalidade, tidas como a causa do comportamento criminoso. Nesse contexto, o profissional behaviorista é contratado a fim de corrigir esses comportamentos. Para tanto, o analista do comportamento deve voltar-se das causas mentais para as relações que produzem o comportamento criminoso, considerando que tanto o comportamento ilegal quanto o legal são igualmente controlados. Além disso, alerta
Holland, o analista do comportamento não pode perder de vista isto: o comportamento do profissional de Psicologia também é o resultado de contingências sociais. É certo que vivemos em uma sociedade hierarquizada, e é da elite que os objetivos de nossa sociedade são geralmente formulados. O autor considera que, ao se inserirem no sistema, os analistas do comportamento poderão ter um alto grau de estabilidade e prestígio, e, em função dessas condições, poderiam facilmente acreditar que merecem esse reconhecimento devido à sua inteligência superior, motivação e direitos. "É tentador, mesmo para os behavioristas, ignorar sua ciência e aceitar o elogio às causas internas" (Holland, 1978, p. 169).

Holland discute ainda que é importante para a elite convencer os menos abastados, ou mesmo os ditos causadores de problemas sociais, de que a situação de miséria na qual se encontram é culpa deles próprios. Nessas condições, até mesmo aqueles que oferecem seu trabalho para modificar comportamentos podem, por vezes, aceitar essas definições que culpabilizam a vítima. Sem exame crítico, o analista do comportamento pode, ao invés de transformar ambientes, empenhar-se em "corrigir a natureza íntima dos indivíduos" (Holland, 1978, p. 170). No entanto, vale lembrar que, na perspectiva analíticocomportamental, se as pessoas de uma sociedade são infelizes e pobres, são as contingências que devem ser modificadas (Holland, 1978; Skinner, 1971/1972; Ullman \& Krasner, 1975), "ou seja, para que se consiga mudar o homem, é necessário, paradoxalmente, mudar as condições sob as quais ele próprio vive" (Carrara, 2005, p. 323).

Vimos que Skinner (1971/1972) considera a análise do comportamento uma ciência dos valores, e ressalta que seu sistema ético traz uma responsabilidade social inerente. Tratar a moralidade em termos de comportamento moral encoraja um olhar para as relações sociais que geram e mantêm comportamentos 
julgados socialmente indesejáveis. Nesse sentido, o alcoolismo e o crime, por exemplo, não devem ser entendidos como produto de personalidades perturbadas, mas como problemas sociais gerados e mantidos por contingências das quais o próprio analista do comportamento pode fazer parte, seja na tentativa de sobrepujar, seja de manter esses problemas.

Essa discussão sugere uma estreita relação entre ciência do comportamento e sociedade, atribuindo à análise do comportamento uma responsabilidade social com respeito às suas práticas de intervenção. Com efeito, engajarse em práticas culturais que promovam a sobrevivência das culturas requer do analista do comportamento um exame crítico das condições que balizam os problemas sociais, bem como do seu papel nesse contexto. Mas isso não basta. É preciso também que o analista do comportamento reflita sobre a sua relação com a sociedade em outra direção. Como a análise do comportamento, como ciência dos valores, considera o conhecimento do homem comum, isto é, da sociedade em geral? Essa questão faz sentido em um contexto científico contemporâneo marcado pelo debate entre dois modelos de ciência: moderno e pós-moderno, que subscrevem, por seu turno, relações distintas e incompatíveis entre ciência e sociedade. Cumpre agora examinar essa questão.

\section{Análise do comportamento: uma ciência dos valores moderna ou pós-moderna?}

O modelo moderno sustenta que a ciência é a única forma de conhecimento verdadeiro, uma vez que é produto da aplicação do método científico. Com esse método, o cientista apreenderia os fatos por meio de observação sistemática, controle e manipulação de variáveis, organizando depois as descrições desses fatos em termos de uma lei geral. Por produzir um conhecimento com base no método científico, a ciência moderna foi considerada a detentora do saber Verdadeiro, tendo "respostas para 'todos' os problemas" (Francelin, 2004, p. 28). Na ciência moderna, o conhecimento científico é subsidiado por um modelo totalitário, na medida em que "nega o caráter racional a todas as formas de conhecimento que não se pautarem pelos seus princípios epistemológicos e pelas suas regras metodológicas" (Santos, 2002, p. 21).

Essa visão proposta pelo modelo de ciência moderna levou a distinções fundamentais entre o conhecimento científico e o conhecimento do senso comum (Morin, 1982/2008; Santos, 2002). A ciência moderna, calcada em uma explicação mecanicista da natureza, desconfia da experiência imediata, considerando-a ilusória. O conhecimento baseado nessa experiência imediata enganadora seria um conhecimento vulgar (Santos, 2002). Nesse sentido, o conhecimento científico opõese ao conhecimento do senso comum: o primeiro, assentado nos fatos, é objetivo e preciso, por isso, verdadeiro; já o segundo sequer pode receber a designação de conhecimento, já que é fundamentado em crenças, opiniões, e, sendo assim, pode induzir ao erro e à falsidade.

Há, aqui, uma relação unilateral entre ciência e sociedade: o especialista (ou cientista) detém o conhecimento Verdadeiro; já o leigo se vale do conhecimento impreciso, falso e arbitrário do senso comum. A ciência moderna caracteriza-se, então, por uma ruptura epistemológica, na qual o conhecimento científico foi cindido qualitativamente do conhecimento do senso comum (Santos, 2002).

Outra expressão da relação desigual entre ciência e senso comum pode ser esclarecida por meio da dicotomia entre fatos e valores. A ciência moderna destaca que o cientista 
deve se atentar apenas para os fatos, e que questões relacionadas aos valores não são de sua alçada, eximindo-se de qualquer relação direta com a sociedade (Marcuse, 1966/2009). Entretanto, ao comprometerse com o cientificismo e sustentar que o conhecimento produzido pela ciência é Verdadeiro, a ciência moderna se põe como modelo de referência para o senso comum. A sociedade passa a depositar total confiança no conhecimento científico e no cientista, pautando-se amiúde neles para tomar decisões. Segundo Marcuse, a separação entre ciência e sociedade, ou entre ciência e valores, foi outrora necessária para que a ciência se desvencilhasse do dogmatismo religioso e pudesse, então, progredir tecnologicamente. No entanto, essa separação, que antes levou ao progresso, agora se tornou destrutiva e regressiva, dado o papel regulador da ciência na sociedade. O cientista pode tentar defender-se dizendo que não é responsável pela aplicação do conhecimento científico no âmbito social, e que isso fica a cargo dos engenheiros e da sanção do governo. Marcuse considera que, mesmo se aceitarmos essa justificativa, ela não presume a neutralidade da ciência em relação à sociedade, de modo que

o cientista permanece responsável como cientista porque o desenvolvimento social e a aplicação da ciência determinam, em considerável medida, o posterior desenvolvimento conceitual interno da ciência. O desenvolvimento teórico da ciência é assim enviesado em uma direção política específica, e a noção de pureza teórica e neutralidade moral é assim invalidada. (Marcuse, 1966/2009, p. 161)

Em outras palavras, o conhecimento científico provê o desenvolvimento de uma tecnologia que age diretamente na sociedade, e as transformações que ocorrem na sociedade, em certa medida, retroalimentam essa cadeia, de modo a influenciar o conhecimento produzido pela ciência. Sob esse prisma, como está do lado dos fatos, o cientista moderno, mesmo sem admitir, dita os valores, isto é, aquilo que deve ou não ser feito com base no pensamento científico. Em suma, no limite, quem decide parece ser o especialista, e quem cumpre, o leigo.

A partir do final do século XIX e início do século XX, o modelo de ciência moderna começou a apresentar sinais de uma crise irreversível (Morin, 1982/2008; Santos, 2002). Um dos indícios dessa crise está circunscrito à relação entre conhecimento científico e conhecimento do senso comum. Em oposição à ciência moderna, o paradigma emergente, ou modelo de ciência pósmoderno, defende uma aproximação entre ciência e sociedade em outras bases. A ciência pós-moderna considera válido $\mathrm{O}$ diálogo com outras formas de conhecimento, "deixando-se penetrar por elas" (Santos, 2002, p. 88). Dentre essas outras formas de conhecimento, avalia como a mais importante o conhecimento do senso comum, que orienta as nossas ações e confere sentido à vida:

A ciência pós-moderna procura reabilitar o
senso comum por reconhecer nessa forma
de conhecimento algumas virtualidades
para enriquecer a nossa relação com o
mundo. É certo que o conhecimento do
senso comum tende a ser um conhecimento
mistificado e mistificador, mas, apesar
disso e apesar de ser conservador, tem
uma dimensão utópica e libertadora que
pode ser ampliada através do diálogo com
o conhecimento científico. (Santos, 2002,
p. 89)

Nessa perspectiva, o conhecimento científico é produzido de acordo com critérios diferentes do conhecimento do senso comum, porém, isso não é empregado para defender a superioridade do primeiro em relação ao segundo; essa diferenciação não subscreve uma relação hierárquica e unilateral, mas considera que o conhecimento do senso comum, deixado a si mesmo, será conservador e autoritário, no entanto, se for alcançado pelo conhecimento científico, poderá 
potencializar uma nova racionalidade. Para isso, a ciência pós-moderna instaura outra ruptura epistemológica: o conhecimento científico só pode ser reconhecido como tal se modificar o senso comum ampliando suas potencialidades emancipatórias, ao mesmo tempo em que se deixa afetar pela racionalidade concreta do senso comum (Santos, 2002). Com efeito, não se trata de converter o senso comum em ciência, mas de reconhecer suas virtualidades, admitindo que esse conhecimento popular possa ser ampliado pelo contato com o conhecimento científico.

$\mathrm{Na}$ verdade, o que se defende é uma aproximação entre ciência e sociedade na qual haja benefícios recíprocos (Santos, 2002). A ciência pode aprender com o conhecimento do leigo, produzindo, por exemplo, um conhecimento concreto, contextualizado à realidade histórica e social. Isso difere do conhecimento da ciência moderna, que é abstruso e, não raro, descontextualizado das demandas sociais, já que muitas vezes é cego pelos ideais de certeza, previsão e controle da natureza. A sociedade, por seu turno, pode valer-se do conhecimento científico para catalisar seus aspectos emancipatórios, no sentido de desenvolver uma reflexão crítica em relação aos problemas sociais, de modo a conquistar a cidadania não apenas individual, mas principalmente coletiva. Porém, notase, aqui, uma diferença: a sociedade usa o conhecimento científico para concretizar aquilo que ela delibera, não o que o cientista quer ou acha que deva ser feito. Em outras palavras, na ciência pós-moderna, o especialista está subjugado à sociedade civil, e não o contrário.

Diante dessa breve análise, percebe-se que, a depender do modelo de ciência adotado, uma relação diferente é estabelecida com o senso comum, ou seja, cada modelo de ciência traz consigo uma interpretação de responsabilidade social distinta, que leva a práticas diferentes. Tendo em vista que o analista do comportamento é um cientista, devemos considerar, então, que ele também é responsável pelas consequências sociais de sua prática.

A proposta ética skinneriana sugere que o bem da cultura seja utilizado como valor de referência para a prática do analista do comportamento. Entretanto, as pessoas com as quais ele vai lidar provavelmente adotam valores distintos. Isso conduz à seguinte indagação: "como deveria agir o analista do comportamento, como profissional eticamente orientado, em sua interação com determinadas populações a fim de modificar operantes e práticas culturais?" (Dittrich \& Abib, 2004, p. 430). Como já foi assinalado, essa prática vai depender do modelo de ciência adotado.

De acordo com a ciência moderna, que detém a Verdade, total e absoluta, o analista do comportamento poderá julgar saber o que é bom para aqueles que requerem sua intervenção, ignorando as suas opiniões, e realizando a tarefa a que se propôs de acordo com seus próprios valores. Transpondo essa discussão para o contexto clínico, à guisa de ilustração, é como se o terapeuta ignorasse o conhecimento que o cliente traz com base em sua história de vida, e definisse os planos e os objetivos da terapia sozinho (Dittrich \& Abib, 2004). Abib (2003) considera que, em uma situação terapêutica, tanto a linguagem própria do cliente quanto a linguagem da análise do comportamento são legítimas, "não se trata de afirmar esta é verdadeira (a linguagem do terapeuta) e aquela é falsa (a da pessoa que conta suas dificuldades)" (Abib, 2003, p. 63). Além disso, Abib também destaca que a linguagem comportamental não é um refinamento da linguagem da sociedade; aquela não é superior a esta última. Um exemplo do cotidiano em que a linguagem comportamentalista se sobrepõe 
à linguagem da comunidade é dado por Pessotti (2011). Essa crônica conta a história de uma aluna de culinária, Florinda, que, após fazer um curso por correspondência sobre Psicologia do comportamento, traduziu as receitas utilizadas na aula empregando termos comportamentalistas. A aluna sugeriu tantas correções na receita que Dona Eufrásia, a senhora que ministrava o curso, sentiu-se inferior e incapaz de publicar seu tão sonhado livro de receitas. O marido de Dona Eufrásia chega a comentar que a aluna havia feito isso "para aparecer", e que "nada do que ela escreveu serve para coisa nenhuma" (Pessotti, 2011, p. 42).

É certo que Skinner, por vezes, criticou a linguagem do senso comum (o vernáculo) alegando que ela "remete a muitos sentimentos e estados da mente" (1990a, p. 1209). E, para Skinner (1978, 1981), uma explicação do comportamento dada nesses termos desvia o olhar das contingências responsáveis pelos problemas sociais. Dito isso, cabe indagar: a crítica de Skinner ao homem autônomo e ao mito das causas internas não seria uma forma de deslegitimar o discurso do senso comum? À primeira vista, sim, se não fosse por declarações skinnerianas em contrário, tais como esta:

Por meio do uso do vernáculo, com suas alusões à história pessoal e à probabilidade de ação, a Psicologia emergiu como uma profissão eficaz, essencial e altamente respeitada. A tentativa de utilizar as aparentes referências [itálicos nossos] a uma mente iniciadora e de converter o vernáculo em linguagem de uma ciência foi, no entanto, um equívoco. (Skinner, 1990a, p. 1209)

Embora Skinner tenha dito que a linguagem do senso comum usualmente recorre a estados mentais, ela não parece ser exclusivamente o alvo da discussão. O problema central reside na linguagem criada por cientistas e filósofos que atribui um estatuto ontológico às eventuais referências do vernáculo a uma mente iniciadora. Em tese, Skinner parece sugerir que não é o senso comum que detém uma ontologia mentalista. Na verdade, são teorias filosóficas e científicas que buscam determinar uma ontologia do vocabulário psicológico empregado pelo senso comum, e, ao fazerem isso, substancializam a mente, entendida, aqui, como agente iniciador do comportamento. Parece que Skinner está chamando a atenção para o que Araújo denominou "equívoco ontológico": o emprego de termos mentais pelo senso comum não significa o compromisso com uma ontologia "explícita e uniforme" (2011, p. 24). Em outras palavras, "as discussões ontológicas não pertencem ao senso comum"; pertencem, isso sim, à Psicologia científica, que busca explicitar uma suposta ontologia de conceitos psicológicos empregados pelo leigo (Araújo, 2011). O que está em jogo não é o emprego de termos mentais pelo senso comum, "mas sim, o estatuto de seus termos transformados em conceitos pertencentes a teorias psicológicas, que seriam submetidas aos critérios estabelecidos para a avaliação de teorias científicas" (Araújo, 2011, pp. 24-25). Em suma, o alvo skinneriano não parece ser a versão leiga do vernáculo, mas a refinada, composta pela linguagem de teorias científicas, mais especificamente, da ciência cognitiva, considerada por Skinner a "ciência da criação da Psicologia” (1990a, p. 1209). São as teorias cognitivistas que hipostasiam os termos psicológicos empregados pelo senso comum, ora assumindo compromissos com uma ontologia mentalista, explicando o comportamento com base em uma mente criadora, ora com uma ontologia materialista, situando o cérebro como criador ou iniciador do comportamento (Skinner, 1990a). A disputa, aqui, é entre ontologias de teorias científicas distintas, como a da Psicologia cognitiva e a da ciência do comportamento, e não entre análise do comportamento e senso comum.

Dito isso, é possível encontrar na teoria 
skinneriana indícios das duas rupturas epistemológicas descritas por Santos (2002). A primeira marca uma diferença entre o conhecimento científico e o conhecimento do senso comum. Embora Skinner admita que o conhecimento científico tenha sua gênese no conhecimento ordinário, quando diz "as leis científicas provavelmente emergiram da sabedoria do artesão" (1974, p. 123), eles não se identificam. Cada um deles tem objetivos e interesses particulares. A diferença, contudo, não incorre em superioridade do conhecimento da ciência em comparação com aquele oriundo do senso comum. Skinner declara que o conhecimento científico não está mais próximo da realidade do que outro tipo de conhecimento:

É um erro. . . dizer que o mundo descrito pela ciência está de um modo ou de outro mais próximo "do que realmente existe", mas também é um erro dizer que a experiência pessoal do artista, compositor, ou poeta está mais próxima "do que realmente existe". Todo comportamento é determinado, direta ou indiretamente, por consequências, e os comportamentos tanto do cientista quanto do não cientista são modelados pelo que realmente existe, mas de maneiras distintas. (Skinner, 1974, p. 127)

Com efeito, as distinções entre conhecimento científico e conhecimento do senso comum não parecem residir na sua proximidade ou não com a realidade, mas no controle de estímulos (Skinner, 1974). A comunidade científica organiza contingências de modo que o cientista descreva leis com as quais possa lidar efetivamente com a natureza, seja explicando, seja prevendo ou modificando o fenômeno de interesse. O homem comum organiza contingências de modo que consiga resolver seus problemas imediatos cotidianos. Nessa perspectiva, cientistas e leigos veem coisas distintas: as contingências dispostas pela comunidade científica cooperam para que o cientista veja corpúsculos ou ondas, e comprimentos de onda; já as contingências mantidas pelo leigo contribuem para que ele veja luz e cores. Nesse caso, "pessoas veem coisas diferentes quando estiveram expostas a diferentes contingências de reforço. Como qualquer outra pessoa, o cientista vê o verde, mas ele também responde de outras maneiras à mesma situação (setting)" (Skinner, 1974, pp. 79-80).

Há também sinais da segunda ruptura epistemológica, na qual a ciência se institui como tal quando se aproxima do senso comum. Skinner sugere uma aproximação da análise do comportamento com o vernáculo, e não com a linguagem de sistemas filosóficos ou científicos que comungam com a noção de agente iniciador, seja na sua versão mentalista (mente), seja na materialista (cérebro). Não obstante, Skinner argumenta que a análise do comportamento poderia ainda ajudar o senso comum ao menos de duas maneiras: "tornando claras as contingências de reforçamento às quais o vernáculo se refere e tornando possível o planejamento de ambientes melhores - ambientes pessoais que solucionariam os problemas existentes, e ambientes maiores, ou culturas, nas quais haveria menos problemas" (1990a, p. 1210). O conhecimento do senso comum poderia, então, usufruir do conhecimento da ciência do comportamento para mudar a vida do indivíduo, e, de um modo mais amplo, da própria cultura, alcançando, respectivamente, a cidadania individual e coletiva. Dito de outro modo, na medida em que a linguagem da análise do comportamento incita descrições de problemas sociais em termos de relações homem-mundo, e não com base em entidades internas ao indivíduo, o senso comum, deixando-se afetar por esse conhecimento, poderia fortalecer suas tendências emancipatórias. Recuperando o exemplo anterior, Abib declara que, ao considerar que tanto a linguagem do terapeuta como a do cliente sejam legítimas, a terapia comportamental poderia conduzir a análise do comportamento à segunda ruptura epistemológica - um indicativo da ciência 
pós-moderna, na perspectiva de Santos (2002). Abib esclarece:

Com a análise compartilhada de contingências, o terapeuta ensina e a pessoa aprende a analisar contingências. A pessoa passa a dominar a linguagem da análise do comportamento. Aí está a segunda ruptura epistemológica. É com ela que a pessoa pode então modificar seus ambientes pessoais e os ambientes mais amplos chamados de culturas. Quer dizer, com essa segunda ruptura epistemológica, a terapia comportamental contribui para ultrapassar o nível propriamente individual da terapia (o de modificar ambientes pessoais) para alcançar os ambientes mais amplos (as culturas), usualmente os ambientes que dão origem a muitos dos problemas dos indivíduos. A terapia adquire uma importante função social [itálicos nossos]. (2003, p. 63)

Por outro lado, a segunda ruptura epistemológica exige outro movimento: a ciência também precisa "sensocomunizarse" (Santos, 2002, p. 91). A análise do comportamento também pode aprender com o conhecimento popular, pois "o senso comum é transparente e evidente; desconfia da opacidade dos objectivos tecnológicos e do esoterismo do conhecimento em nome do princípio da igualdade do acesso ao discurso, à competência cognitiva e à competência linguística" (Santos, 2002, p. 89). Nesse sentido, a ciência do comportamento, deixando-se penetrar pelo conhecimento do senso comum, correria um menor risco de se tornar uma proposta científica abstrusa, e alienada das demandas e dos problemas sociais concretos.

A aproximação com o conhecimento do senso comum tem implicações sociais diretas para as pretensões da análise do comportamento de promover a sobrevivência das culturas em intervenções de amplo alcance, como no caso do planejamento cultural. Ter no horizonte que o conhecimento do analista do comportamento não está mais próximo da realidade do que o conhecimento do homem comum significa, entre outras coisas, respeitar o senso comum no processo de delinear práticas culturais. O contrário disso seria o planejador cultural adotar o valor de sobrevivência da cultura para propor novas práticas, a despeito do interesse dos outros membros do grupo. Pautado pelo modelo de ciência moderna, ele pode negligenciar o fato de que nem todas as pessoas possuem esse mesmo valor como referência, e que estão mais interessadas em valores tradicionais, como liberdade, felicidade, criatividade, amor. Por outro lado, uma ciência pós-moderna considera que uma relação respeitosa com o senso comum é indispensável. Nesses moldes, se o analista do comportamento optar por adotar o valor de sobrevivência das culturas como referência, ao se deparar com os sistemas leigos, deve ao menos buscar um diálogo com eles (Dittrich \& Abib, 2004).

Não entanto, se a sobrevivência das culturas for adotada como um valor para nortear a prática do analista do comportamento, resta, então, indagar: de qual cultura estamos tratando? Esse questionamento remete novamente ao debate entre ciência moderna e pós-moderna. Para ilustrar esse ponto, conjecturemos o seguinte: tomando por base a ciência moderna, o analista do comportamento, como especialista, poderia considerar a cultura analítico-comportamental como a melhor. Ora, ele, como conhecedor dos fatos, teria condições de avaliar o que deveria ou não ser feito. Desse modo, sua prática seria orientada de acordo com a sua concepção do que seria uma cultura melhor. Por outro lado, o analista do comportamento comprometido com o modelo de ciência pósmoderna tenderia a não adotar uma postura unilateral como na ciência moderna, mas, por meio de uma aproximação com a sociedade, poderia propor novas práticas que atendessem também as necessidades dos indivíduos, e que promovessem, igualmente, os valores tradicionais, como liberdade, segurança, saúde etc. Lopes considera que, do ponto de vista ético, espera-se que o representante de uma cultura defenda a sobrevivência de sua cultura, mas de modo a respeitar a sobrevivência de outras culturas, ou melhor, "que a sobrevivência de uma cultura não se dê às custas da extinção de outras" (2006, p. 54). Tal relação, segundo esse autor, implica um respeito à diversidade 
cultural. Assim, o termo sobrevivência das culturas deverá sempre ser considerado no plural, o que indica o pressuposto de que não apenas uma cultura deva sobreviver. Em outras palavras, a eficácia da intervenção só será alcançada mediante a promoção da diversidade de culturas: a cultura do analista do comportamento, a cultura do senso comum, e assim por diante.

\section{Considerações finais}

A análise do comportamento é uma ciência com filosofia, métodos e técnicas próprias. Possui também seu próprio sistema ético, por meio do qual propõe que as práticas sejam avaliadas. Nesse contexto, Skinner (1971/1972) declarou que a ciência do comportamento é também uma ciência dos valores. Essa assertiva precisa ser problematizada: ela sugere que a ciência dita os valores? Isto é, que, em última instância, o conhecimento vulgar precisa ser substituído pelo conhecimento científico, já que esse último está do lado dos fatos, da Verdade? Ou que não há demarcações fixas e rígidas entre fatos e valores, de sorte que o conhecimento científico se deixa penetrar pelo conhecimento do senso comum, e vice-versa? Enfim, que ciência e senso comum podem cooperar, pois são conhecimentos igualmente legítimos? Essas indagações subsidiam a ilação de que modelos científicos diferentes levam a relações entre ciência e senso comum distintas e incompatíveis, com consequências sociais igualmente distintas.
Skinner (1974, 1990a, 1990b) advoga algumas teses que aproximam a análise do comportamento do modelo pós-moderno de ciência: embora sejam diferentes, não considera o conhecimento científico superior ao do senso comum. Sobre esse ponto, Skinner ainda diz mais: "o experimento formalizado da ciência, somado à experiência prática do indivíduo em um conjunto complexo de circunstâncias, oferece a melhor base para a ação eficiente" (1953/2007, p. 408). Nesse sentido, Skinner parece defender a cooperação, ou melhor, a ação conjunta do analista do comportamento com o leigo, e não um isolamento entre eles. Ademais, uma ciência pós-moderna dos valores parece ter condições de enfrentar as críticas comumente endereçadas ao behaviorismo skinneriano, pois o analista do comportamento, ao colocar seu saber como ferramenta para auxiliar o senso comum na busca pela cidadania, inscreve-se como uma ciência democrática e em prol da transformação da sociedade.

Por fim, Carvalho Neto, Alves e Baptista consideram que uma análise behaviorista radical exige que $\mathrm{o}$ cientista se volte para o mundo concreto na busca de explicações para as ações das pessoas, o que sugere que mudar o comportamento é mudar o mundo, e não apenas as representações sobre ele. Essa concepção vincula necessariamente a análise do comportamento a um engajamento político e social, a ponto de se poder dizer que "fazer behaviorismo seria fazer, mesmo que indiretamente, política" (Carvalho Neto, Alves, \& Baptista, 2007, p. 42).

\section{Anne Carolynne Bogo}

Graduanda do curso de Psicologia da Universidade Estadual de Maringá, Maringá - PR - Brasil.

E-mail: annebogo@hotmail.com

\section{Carolina Laurenti}

Doutora em Filosofia pela Universidade Federal de São Carlos, e professora adjunta do Departamento de Psicologia da Universidade Estadual de Maringá, Maringá - PR - Brasil.

E-mail: laurenticarol@gmail.com

Endereço para envio de correspondência:

Rua Pioneiro João Nunes, 835, casa A, Maringá - PR. CEP: 87047-540

Recebido 20/12/2011, 1a Reformulação 21/06/2012, Aprovado 15/10/2012. 


\section{Referências}

Abib, J. D. (2001). Teoria moral de Skinner e desenvolvimento humano. Psicologia: Reflexão e Crítica, 14(1), 107-117.

Abib, J. A. D. (2003). Behaviorismo radical e interpretação. In M. Z. da S. Brandão, F. C. de S. Conte, F. S. Brandão, Y. K. Ingberman, C. B. de Moura, \& V. M. da Silva, et al. (Orgs.). Sobre comportamento e cognição: a história e os avanços, a seleção por conseqüểncias em ação (pp. 57-65). Santo André, SP: Esetec.

Abib, J. A. D. (2008). Skinner, Darwin e Dawkins: encontros. In ABPMC, Boletim contexto, 1-5. Recuperado em 19 dez., 2011, de http://www. abpmc.org.br/site/wp-content/uploads/2011/06/ abib.pdf.

Araújo, S. F. (2011). Psicologia e neurociência: uma avaliação da perspectiva materialista no estudo dos fenômenos mentais (2a ed. rev. ampl.). Juiz de Fora, MG: Editora da UFJF.

Carrara, K. (2005). Behaviorismo radical: crítica e metacrítica. São Paulo: UNESP.

Carvalho Neto, M. B., Alves, A. C. P., \& Baptista, M. Q. G. (2007). A "consciência" como um suposto antídoto para a violência. Revista Brasileira de Terapia Comportamental e Cognitiva, 9(1), 27-44.

Dittrich, A., \& Abib, J. A. D. (2004). O sistema ético skinneriano e consequências para a prática dos analistas do comportamento. Psicologia: Reflexão e Crítica, 17(3), 427-433.

Francelin, M. M. (2004, set./dez.). Ciência, senso comum e revoluções científicas: ressonâncias e paradoxos. Ciência da Informação, 33(3), 26-34.

Gongora, M. A. N. (2003). Noção de psicopatologia na análise do comportamento. In C. E. Costa, J. C. Luzia \& H. H. N. Sant'Anna (Orgs.). Primeiros passos em análise do comportamento e cognição (pp. 93-109). Santo André, SP: Esetec.

Holland, J. G. (1978). Behaviorism: Part of the problem or part of the solution? Journal of Applied Behavior Analysis, 11(1), 163-174.

Holpert, E. C. (2004). Questões sociais na análise do comportamento: artigos do Behavior and Social Issues (1991-2000). Revista Brasileira de Terapia Comportamental e Cognitiva, 6(1), 1-16.

Lopes, C. E. (2006). Subjetividade, privacidade e ética. In H. J. Guilhardi \& N. C. de Aguirre (Orgs.). Sobre comportamento e cognição: expondo a variabilidade (pp. 51-56). Santo André, SP: Esetec.

Marcuse, H. (2009). A responsabilidade da ciência. Scientiae Studia, 7(1), 159-164 (Trabalho original publicado em 1966).

Morin, E. (2008). Ciência com consciência. Rio de Janeiro: Bertrand Brasil (Trabalho original publicado em 1982).

Oliveira, W. (2001). Terapia por contingências: o terapeuta como comunidade verbal anti-internalista. In H. J. Guilhardi, M. B. B. P., Madi, P. P. Queiroz \& M. C. Scoz (Orgs.). Sobre comportamento e cognição: expondo a variabilidade (pp. 297-312). Santo André, SP: Esetec.

Pessotti, I. (2011, junho). Receita de rosca de nozes. In ABPMC, Boletim contexto (pp. 42-43). Recuperado em 10 ago., 2011, de http://www.abpmc.org.br/site/ wp-content/uploads/2011/07/34.pdf.

Santos, B. S. (2002). Um discurso sobre as ciências. Porto: Afrontamento.

Skinner, B. F. (1972). O mito da liberdade (L. Goulart \& M. L. F. Goulart, trads.). Rio de Janeiro: Bloch (Trabalho original publicada em 1971).

Skinner, B. F. (1974). About behaviorism. New York: Alfred A. Knopf.

Skinner, B. F. (1978). Reflections about behaviorism and society. Englewood Cliffs, NJ: Prentice Hall.

Skinner, B. F. (1981, Jul. 31). Selection by consequences. Science, 213(4507), 501-504.

Skinner, B. F. (1989). Recent issues in the analysis of behavior. Columbus: Merrill Publishing Company.

Skinner, B. F. (1990a). Can psychology be a science of mind? American Psychologist, 45(11), 1206-1210.

Skinner, B. F. (1990b). To know the future. The Behavior Analyst, 13(2), 103-106.

Skinner, B. F. (2007). Planejamento de uma cultura. In Ciência e comportamento humano (J. C. Todorov \& R. Azzi, Trad., pp. 399-408). São Paulo: Martins Fontes (Trabalho original publicado em 1953).

Szasz, T. S. (1980). Ideologia e doença mental. Rio de Janeiro: Zahar (Trabalho original publicado em 1970).

Tourinho, E. Z. (2006, jan./jun.). Relações comportamentais como objeto da psicologia: algumas implicações. Interação em Psicologia, 10(1), 1-8.

Ullman, L., \& Krasner, L. (1975). A psychological approach to abnormal behavior. Englewood Cliffs: Prentice-Hall. 